\title{
Analisis Pengaruh Variasi Flow Rate Gas Pelindung pada Pengelasan FCAW-G terhadap Struktur Mikro dan Kekuatan Mekanik Sambungan Material Grade A
}

\author{
Nabielah Khiyaarul A., Nur Syahroni, dan Yoyok S. Hadiwidodo \\ Departemen Teknik Kelautan, Fakultas Teknologi Kelautan, Institut Teknologi Sepuluh Nopember (ITS) \\ e-mail: nabielahka@gmail.com
}

\begin{abstract}
Abstrak-Pengelasan merupakan hal yang tidak dapat dipisahkan dari dunia industri maritim terutama perkapalan karena hampir keseluruhan konstruksi badan kapal disambung dengan cara dilas. Salah satu metode pengelasan yang paling sering digunakan adalah FCAW (Flux Cored Arc Welding). Pengelasan FCAW sering digunakan karena produktivitasnya yang tinggi. Dalam penerapannya, pengelasan FCAW dapat digunakan dengan atau tanpa gas pelindung. Gas pelindung berfungsi sebagai pelindung logam las agar tidak terjadi interaksi dengan udara sekitar juga mempengaruhi kestabilan nyala busur yang dapat memengaruhi kinerja dari welder pada saat mengelas. Dalam penelitian ini akan dianalisis bagaimana pengaruh variasi flow rate gas pelindung terhadap struktur mikro, kekerasan, dan kekuatan tariknya. Variasi flow rate gas pelindung yang digunakan adalah $14 \mathrm{~L} /$ menit, $16 \mathrm{~L} / \mathrm{menit}$, dan $18 \mathrm{~L} / \mathrm{menit}$. Dari hasil pengujian akan didapatkan hasil pengaruh variasi flow rate gas pelindung terhadap struktur mikro, kekerasan, dan kekuatan tarik.
\end{abstract}

Kata Kunci-Pengelasan, Fcaw, Flow Rate, Gas Pelindung, Struktur Mikro, Kekerasan, Uji Tarik.

\section{PENDAHULUAN}

$\mathrm{P}$ ENGELASAN adalah suatu teknik penyambungan logam dengan menggunakan energi panas. Pengelasan merupakan hal yang penting dan tidak bisa dipisahkan dalam dunia industri maritim terutama perkapalan karena hampir keseluruhan konstruksi badan kapal disambung dengan cara dilas. Salah satu metode pengelasan yang paling sering digunakan adalah FCAW (Flux Cored Ard Welding). FCAW merupakan salah satu jenis las busur listrik dengan elektroda tubular. Pengelasan FCAW sering digunakan karena produktivitasnya yang tinggi. Pasokan elektroda diumpankan secara kontinu melalui sebuah gulungan. Berdasarkan metode pelindung, pengelasan FCAW dibedakan menjadi dua yaitu FCAW-SS (Shelf Shielding) dan FCAW-G (Gas). Kedua metode tersebut sama-sama menghasilkan terak atau yang biasa disebut slag. FCAW-SS perlindungannya berasal dari gas hasil penguapan reaksi inti fluks sedangkan FCAW-G perlindungannya tidak hanya dari penguapan reaksi inti fluks juga mendapatkan tambahan gas pelindung dari luar sistem.

Gas pelindung atau shielding gas merupakan komponen penting dalam proses pengelasan. Gas pelindung berfungsi sebagai pelindung logam las agar tidak terjadi interaksi dengan udara sekitar. Selain itu, gas pelindung juga

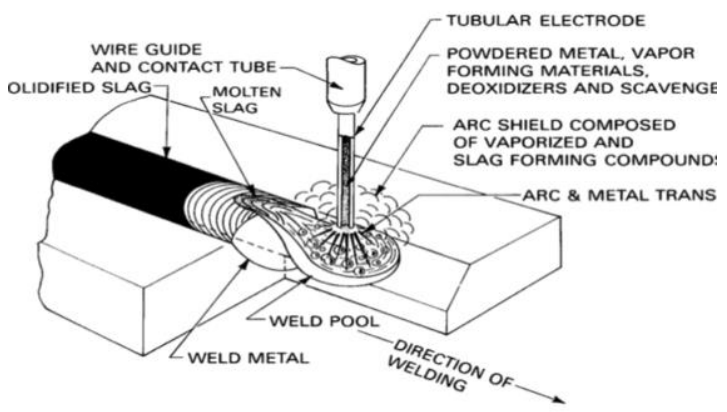

Gambar 1 Skema Las FCAW

mempengaruhi kestabilan nyala busur yang dapat memengaruhi kinerja dari welder pada saat mengelas. Ketidaksempurnaan pada gas pelindung akan memengaruhi hasil pengelasan dan kemungkinan terjadinya cacat las tinggi. Pengelasan FCAW umumnya menggunakan gas $\mathrm{CO}_{2}$ atau dapat dengan campuran $\mathrm{CO}_{2}$ dengan Argon sebagai gas pelindung. Tetapi untuk menghindari logam las terkontaminasi udara luar atau menghindari porositas maka harus dilakukan pemilihan fluks yang mengandung atau mempunyai sifat pengikat oksigen atau deoxydizer.

\section{URAIAN PENELITIAN}

\section{A. Flux Cored Arc Welding}

Pengelasan adalah salah satu teknik penyambungan logam dengan cara mencairkan sebagian logam induk dan logam pengisi dengan atau tanpa tekanan dan dengan atau tanpa logam tambahan dan menghasilkan sambungan yang kontinu [1].

Flux Cored Arc Welding (FCAW) adalah las busur listrik dengan fluks terinti di dalam kawat las (tubular). Las FCAW adalah kombinasi antara proses pengelasan SMAW dan GMAW. Proses las FCAW mirip dengan proses las GMAW, yaitu dengan melelehkan logam induk menggunakan elektroda yang diumpankan secara kontinyu melalui sebuah gulungan. Elektroda yang digunakan mengandung fluks yang pada saat proses pengelasan ikut terbakar dan menghasilkan terak las atau slag seperti proses pengelasan SMAW. Visualisasi pengelasan FCAW ditunjukkan pada Gambar 1.

Berdasarkan jenis pelindungnya, FCAW dibedakan menjadi dua jenis: 
1. Self-Shielding (FCAW-SS), yaitu perlindungannya berasal dari penguapan reaksi inti fluks tanpa adanya tambahan pelindung.

2. Shielding Gas (FCAW-G), perlindungannya berasal dari penguapan reaksi inti fluks dan dengan tambahan gas pelindung. Pada umumnya menggunakan gas $\mathrm{CO}_{2}$ atau menggunakan campuran $\mathrm{CO}_{2}$ dan Argon dengan perbandingan 70:30 atau 80:20.

\section{B. Material Baja Grade A}

Material baja Grade KI-A termasuk baja dengan kandungan karbon rendah atau mild steel dengan jumlah karbon maksimum 0,21\% dari rentang 0,025\%- 0,25\%. Sifat mekanik dari baja grade KI-A dapat dilihat pada Tabel 1 dan komposisi kimia baja grade KI-A dapat dilihat pada Tabel 2.

Tabel 1.

Sifat Mekanik Baja Grade A (BKI Vol. V, 2014)

\begin{tabular}{cccc}
\hline \hline & Yield strength & Tensile strength & Elongation \\
Grade & {$\left[\mathrm{N} / \mathrm{mm}^{2}\right]$} & {$\left[\mathrm{N} / \mathrm{mm}^{2}\right]$} & $\begin{array}{c}{[\%]} \\
\text { min. }\end{array}$ \\
& min. & & 22 \\
\hline KI-A & 235 & $400-520$ & 22 \\
\hline \hline
\end{tabular}

Tabel 2.

Komposisi Kimia Baja Grade A (BKI Vol. V, 2014)

\begin{tabular}{cc}
\hline \hline Komposisi Kimia (\%) & Grade KI-A \\
\hline $\mathrm{C}_{\max }$ & 0,21 \\
$\mathrm{Mn}_{\min }$ & $2,5 \times \mathrm{C}$ \\
$\mathrm{Si}_{\max }$ & 0,50 \\
$\mathrm{P}_{\max }$ & 0,035 \\
$\mathrm{~S}_{\max }$ & 0,035 \\
\hline \hline
\end{tabular}

Elemen yang selalu terdapat dalam baja yaitu karbon, mangan, fosfor, sulfur, dan silikon. Selain itu elemen lain juga ditambahkan untuk medapatkan karakteristik baja yang berbeda. Fungsi karbon dalam baja adalah sebagai unsur pengeras dengan mencegah dislokasi bergeser pada kisi kristal (crystal lattice) atom besi. Penambahan kandungan karbon pada baja dapat meningkatkan kekerasan (hardness) dan kekuatan tariknya (tensile strength), namun di sisi lain membuatnya menjadi getas (brittle) serta menurunkan keuletannya (ductility).

\section{Struktur Mikro Daerah Pengelasan}

Sebagaimana diketahui bahwa logam pada hasil pengelasan dapat dikategorikan menjadi tiga bagian, yaitu: base metal (benda kerja awal), heat affected zone (daerah terpengaruh panas) dan weld zone (logam las).

1. Base metal adalah bagian logam dasar dimana panas dan suhu pengelasan tidak menyebabkan terjadinya perubahan-perubahan struktur maupun sifat pada logam tersebut.

2. Heat Affected Zone (HAZ) adalah logam dasar yang bersebelahan dengan logam las yang selama proses pengelasan mengalami siklus termal pemanasan dan pendinginan cepat sehingga daerah ini yang paling kritis dari sambungan las.

3. Weld metal adalah bagian dari logam yang pada waktu pengelasan mencair dan kemudian membeku, komposisi logam las terdiri dari komponen logam induk dan bahan tambah dari elektroda.

\section{METODOLOGI PENELITIAN}

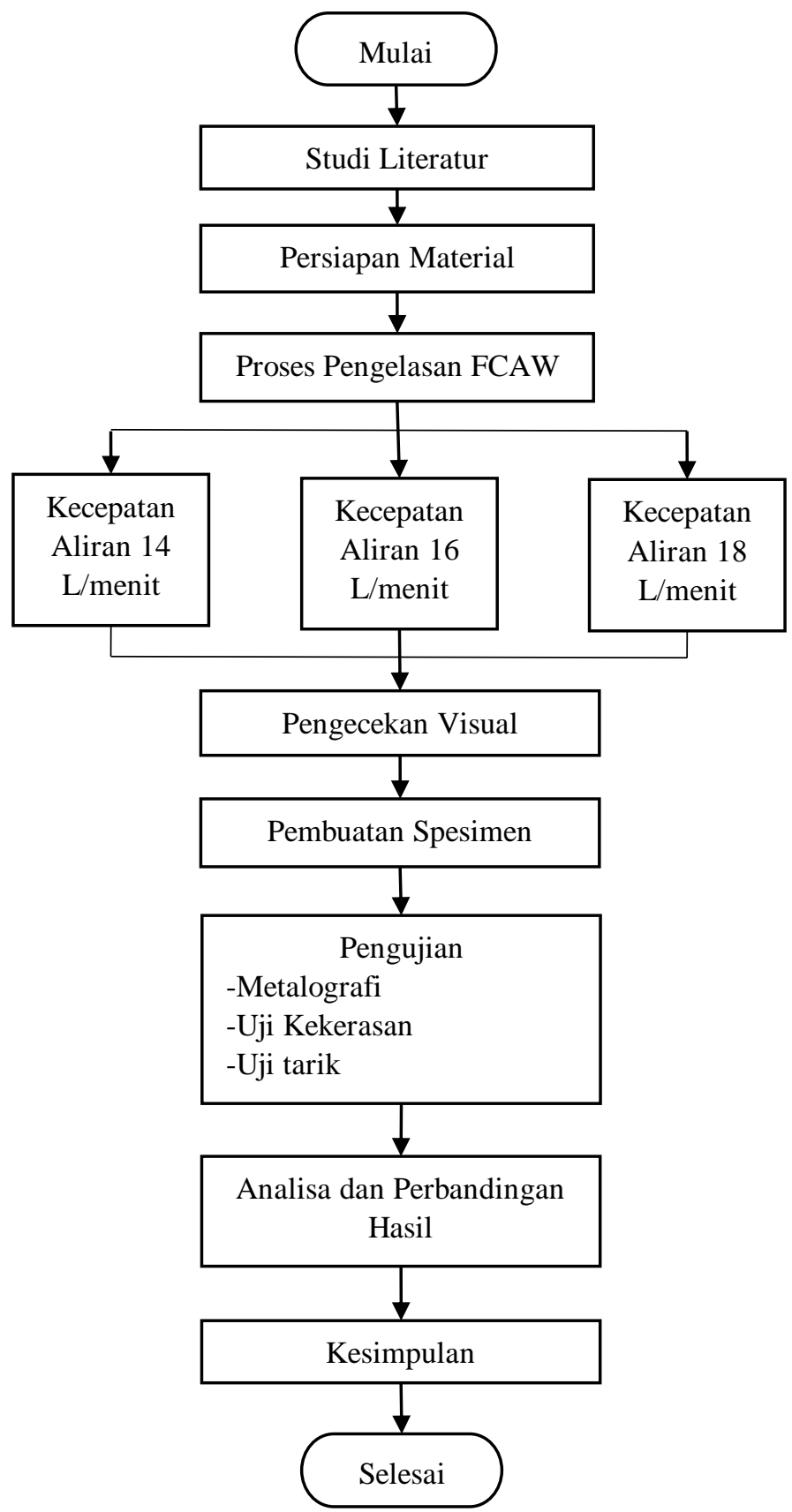

Gambar 2. Diagram alir penelitian.

Langkah awal dalam pengerjaan penelitian ini adalah dengan mencari literatur yang relevan dan mendukung baik secara teori maupun teknis. Kemudian melakukan persiapan material meliputi jenis, jumlah, ukuran material baja maupun elektroda, dan komponen-komponen pendukung lainnya seperti backing material dan stopper. Setelah itu dilakukan pengelasan sesuai parameter yang ditentukan. Setelah dilakukan pengelasan, hasil pengelasan dicek secara visual 
untuk memeriksa kondisi baik atau tidaknya hasil pengelasan tersebut. Kemudian dilakukan pengujian untuk mengetahui pengaruh variasi flow rate gas pelindung terhadap struktur mikro dan kekuatan mekanik. Langkah terakhir adalah dengan melakukan analisa terhadap hasil pengujian dan penarikan kesimpulan. Urutan pengerjaan penelitian yang dilaksanakan mengikuti diagram alir sebagaimana ditunjukkan pada Gambar 2.

Pengelasan yang dilakukan adalah dengan memvariasikan flow rate gas pelindung dengan besar $14 \mathrm{~L} / \mathrm{menit}, 16 \mathrm{~L} / \mathrm{menit}$, dan $18 \mathrm{~L} /$ menit pada sambungan material baja Grade A dengan ketebalan $8 \mathrm{~mm}$. Elektroda yang digunakan adalah tipe E71T-1 dengan gas pelindung $\mathrm{CO}_{2}$ 99,99\%. Arus (Ampere) dan Tegangan (Volt) yang digunakan sama.

Pada tahap persiapan material dilakukan pemotongan spesimen sebanyak enam buah pelat dengan ukuran masingmasing $400 \times 250 \mathrm{~mm}$. kemudian dilakukan pembuatan kampuh, pembersihan material, pemasangan stopper dan backing material.

Pada tahap pembuatan spesimen, bentuk serta ukuran ditentukan oleh standard dan kapasitas mesin uji. Digunakan satu spesimen yang sama pada pengujian mikro dan kekerasan. Pertama dilakukan pemotongan spesimen dengan ukuran $60 \mathrm{~mm} \times 20 \mathrm{~mm} \times$ tebal material. Permukaan yang akan diamati dihaluskan dengan menggunakan kertas gosok dari yang paling kasar sampai yang paling halus. Proses ini disebut dengan proses grinding. Kemudian permukaan spesimen yang akan diuji dipoles dengan menggunakan pasta alumina hingga benar-benar halus.

Untuk uji mikro setelah permukaan spesimen dipoles dilakukan pengetsaan yaitu dengan mencelupkan atau meneteskan reaktan selama 1-5 detik kemudian dibilas dan dikeringkan. Tujuan dari pengetsaan adalah untuk mengkorosikan permukaan yang telah halus akibat proses grinding dan polishing agar dapat diamati.

Pembuatan spesimen uji tarik dimensinya berdasarkan BKI Vol. VI Rules for Welding. Yaitu dengan panjang $400 \mathrm{~mm}$, panjang parallel $62 \mathrm{~mm}$, lebar parallel $25 \mathrm{~mm}$, dan radius $25 \mathrm{~mm}$.

Proses pengujian metalografi dilakukan pengambilan foto mikro dari spesimen yang telah dipersiapkan sebelumnya. Pengambilan foto dilakukan pada daerah weld metal dan fusion line dengan menggunakan miroskop optik.

Proses pengujian kekerasan Vickers dilakukan dengan penekanan indentor intan dengan alas berbentuk persegi. Penekanan dilakukan dengan beban $10 \mathrm{kgf}$ selama 15 detik. Pengujian dilakukan pada tiga daerah pengelasan yaitu: weld metal, HAZ, dan base metal. Pada masing-masing daerah pengelasan dilakukan sebanya tiga kali penekanan untuk mengetahui distribusi kekerasan sehingga diperoleh gambaran perubahan kekerasan akibat proses pengelasan.

Pengujian tarik dilakukan dengan menggunakan Universal Testing Machine yang langsung dihubungkan dengan plotter sehingga dapat diperoleh grafik hubungan beban tarikan $(\mathrm{kN})$ dan regangan $(\mathrm{mm})$ yang memberikan informasi data berupa tegangan yield, tegangan ultimate dan elongation atau pertambahan panjang spesimen uji yang telah dilakukan pengujian. Pengujian dilakukan dengan menaikkan beban tarik hingga spesimen uji tersebut patah.

\section{ANALISIS HASIL PENELITIAN}

\section{A. Analisis Hasil Pengamatan Visual}

Analisa Visual dilakukan untuk memeriksa kualitas hasil pengelasan, ada atau tidaknya cacat las, perlu atau tidaknya dilakukan perbaikan ataupun pengulangan. Kriteria penerimaan cacat las berdasarkan ISO 5817.

Setelah dilakukan analisa secara visual, terdapat adanya cacat las incompletely filled groove (Gambar 3c) pada hasil pengelasan yang ketiga yaitu dengan flow rate gas pelindung sebesar $18 \mathrm{~L} /$ menit dan dalam batas yang masih dapat diterima yaitu $\mathrm{h} \leq 0.25 \mathrm{t}$ atau maksimal $2 \mathrm{~mm}$.

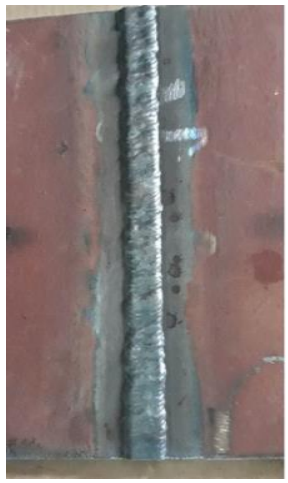

(a)

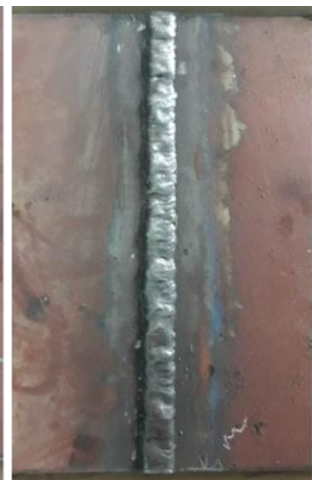

(b)

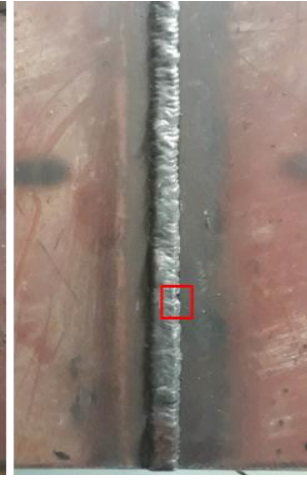

(c)
Gambar 3. Hasil pengelasan dengan variasi gas pelindung, (a) $14 \mathrm{~L} / \mathrm{menit}$, (b) $16 \mathrm{~L} /$ menit, (c) $18 \mathrm{~L} / \mathrm{menit}$.

\section{B. Analisis dan Hasil Uji Mikro}

Pada baja karbon rendah, struktur mikro didominasi oleh ferit dan perlit. Pada hasil foto mikro ferit berwarna putih atau terang sedangkan perlit berwarna kelabu atau lebih gelap. Hasil foto mikro untuk pengelasan FCAW-G dengan variasi flow rate gas pelindung adalah ditunjukkan pada Gambar 4 hingga Gambar 6.

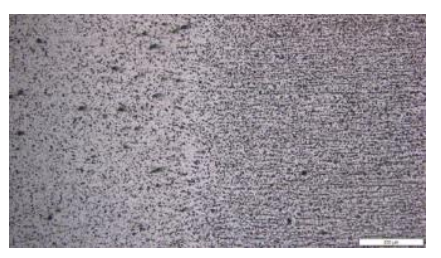

(a)

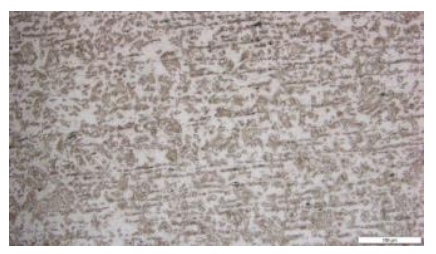

(b)
Gambar 4. Hasil foto mikro pengelasan dengan flow rate $14 \mathrm{~L} /$ menit (a) pada fusion line, (b) weld metal.

Pada pengelasan dengan flow rate gas pelindung sebesar $14 \mathrm{~L} /$ menit garis fusion line atau garis gabungan antara weld metal dengan HAZ terlihat dengan jelas. Struktur perlit terlihat halus. 


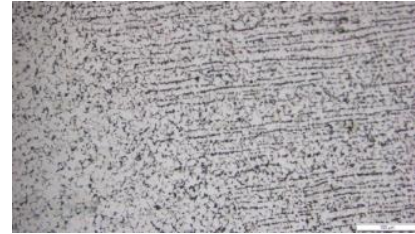

(a) (b)

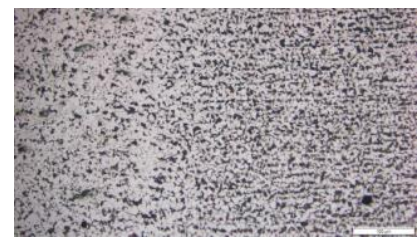

Gambar 5. Hasil foto mikro pengelasan dengan flow rate $16 \mathrm{~L} /$ menit (a) pada fusion line, (b) weld metal.

Pada pengelasan dengan flow rate gas pelindung sebesar $16 \mathrm{~L} /$ menit garis fusion line terlihat jelas namun lebih samar dari sebelumnya (pengelasan dengan flow rate gas pelindung sebesar $14 \mathrm{~L} / \mathrm{menit})$. Terlihat terjadi peningkatan jumlah perlit.

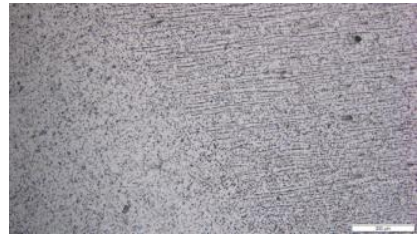

(a)

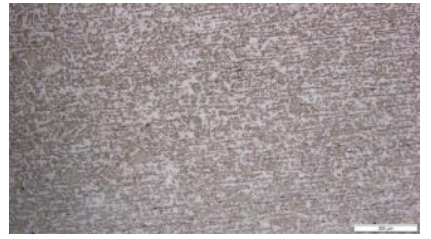

(b)
Gambar 6. Hasil foto mikro pengelasan dengan flow rate $18 \mathrm{~L} /$ menit (a) pada fusion line, (b) weld metal.

Pada pengelasan dengan flow rate gas pelindung sebesar $18 \mathrm{~L} /$ menit garis fusion line terlihat paling samar dari dua pengelasan sebelumnya (pengelasan dengan flow rate gas pelindung sebesar $14 \mathrm{~L} /$ menit dan $16 \mathrm{~L} /$ menit). Terlihat terjadi peningkatan jumlah struktur perlit.

\section{Analisa Hasil Uji Kekerasan Vickers}

Uji kekerasan Vickers dilakukan penekanan sebanyak tiga kali pada tiap daerah. Dengan beban sebesar $10 \mathrm{kgf}$ selama 15 detik. Setelah dilakukan uji kekerasan pada ketiga spesimen didapatkan data sebagaimana ditunjukkan pada Gambar 7 hingga Gambar 9 dan Tabel 3 hingga Tabel 6.

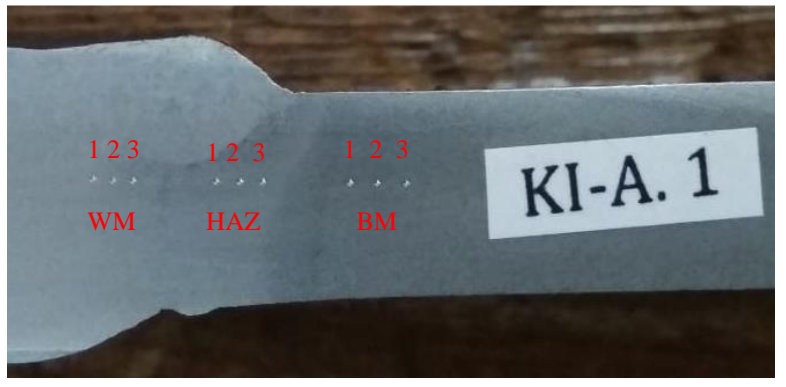

Gambar 7. Hasil uji kekerasan pada spesimen 1 flow rate $14 \mathrm{~L} /$ menit

Tabel.3.

Hasil uji kekerasan pada spesimen 1 flow rate $14 \mathrm{~L} /$ menit

\begin{tabular}{llllc}
\hline \hline \multirow{2}{*}{ Area } & \multicolumn{4}{c}{ Hardness Vickers } \\
\cline { 2 - 5 } & 1 & 2 & 3 & Rata-Rata \\
\hline BM & 139,51 & 144,26 & 141,99 & 141,92 \\
HAZ & 151,61 & 150,92 & 147,47 & 150,00 \\
WM & 166,44 & 172,91 & 171,81 & 170,39 \\
\hline \hline
\end{tabular}

Dari pengujian kekerasan yang dilakukan pada spesimen 1 yaitu pengelasan dengan flow rate gas pelindung sebesar 14 $\mathrm{L} /$ menit menunjukkan adanya peningkatan kekerasan dari daerah base metal terhadap HAZ dan weld metal. Nilai kekerasan rata-rata pada daerah base metal adalah 141,92 $\mathrm{HV}$, pada daerah HAZ adalah 150,00 HV, dan pada daerah weld metal kekerasan rata-ratanya adalah 170,39 HV.

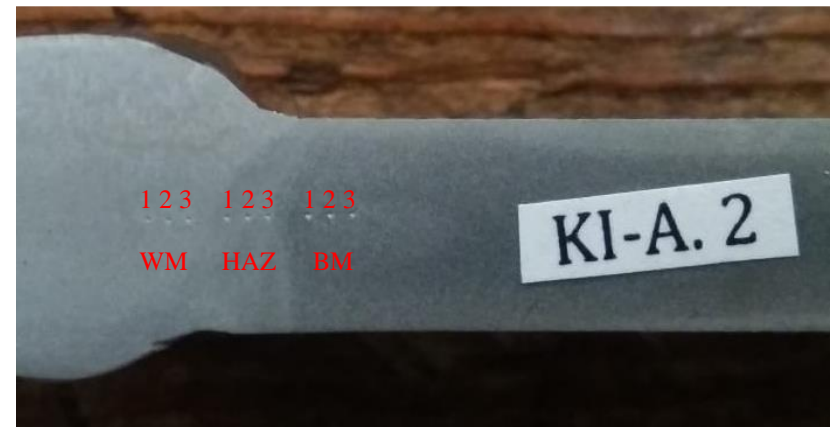

Gambar 8. Hasil uji kekerasan pada spesimen 2 flow rate $16 \mathrm{~L} / \mathrm{menit}$

Tabel.4.

Hasil uji kekerasan pada spesimen 2 flow rate $16 \mathrm{~L} / \mathrm{menit}$

\begin{tabular}{llllc}
\hline \hline \multirow{2}{*}{ Area } & \multicolumn{4}{c}{ Hardness Vickers } \\
\cline { 2 - 5 } & 1 & 2 & 3 & Rata-Rata \\
\hline BM & 142,58 & 145,11 & 148,50 & 145,40 \\
HAZ & 154,29 & 154,82 & 153,09 & 154,07 \\
WM & 188,76 & 188,94 & 190,30 & 189,33 \\
\hline \hline
\end{tabular}

Berdasarkan pengujian kekerasan pada spesimen 2, yaitu pengelasan dengan flow rate gas pelindung $16 \mathrm{~L} /$ menit menunjukkan terjadi peningkatan kekerasan pada daerah HAZ dan weld metal terhadap daerah base metal. Nilai kekerasan rata-rata pada daerah base metal adalah 145,40 HV. Sedangkan pada daerah HAZ nilai kekerasan rataratanya adalah 154,07 HV dan pada daerah weld metal nilai kekerasan rata-ratanya adalah 189,33 HV.

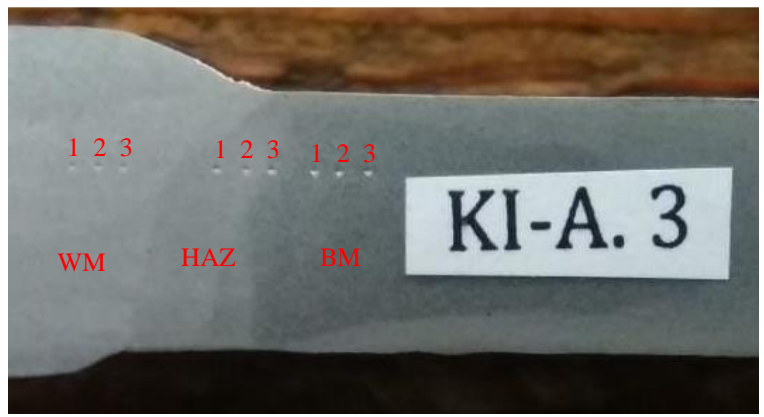

Gambar 9. Hasil uji kekerasan pada spesimen 3 flow rate $18 \mathrm{~L} / \mathrm{menit}$

Tabel.5.

Hasil uji kekerasan pada spesimen 3 flow rate $18 \mathrm{~L} /$ menit

\begin{tabular}{llccc}
\hline \hline \multirow{2}{*}{ Area } & \multicolumn{4}{c}{ Hardness Vickers } \\
\cline { 2 - 5 } & 1 & 2 & 3 & Rata-Rata \\
\hline BM & 162,38 & 171,81 & 167,19 & 167,13 \\
HAZ & 170.14 & 173.81 & 172.54 & 172,16 \\
WM & 203,96 & 206,27 & 207,10 & 205,78 \\
\hline \hline
\end{tabular}


Berdasarkan hasil pengujian pada spesimen 3 yaitu pengelasan dengan flow rate gas pelindung sebesar 18 $\mathrm{L} /$ menit menunjukkan terjadi peningkatan kekeasan pada derah HAZ dan weld metal terhadap daerah base metal. Nilai kekerasan rata-rata pada daerah base metal adalah 167,13 HV. Nilai kekerasan rata-rata pada daerah HAZ adalah 172,16 HV dan pada daerah weld metal nilai kekerasan rataratanya adalah sebesar 205,78 $\mathrm{HV}$.

Kemudian dihitung rata-rata kenaikan nilai kekerasan pada tiap-tiap hasil pengelasan untuk mengetahui seberapa besar presentase pengaruh kenaikan flow rate gas pelindung terhadap nilai kekerasan material pada tiap-tiap daerah seperti yang telah disajikan pada Tabel 6 .

Tabel.6.

Nilai Kekerasan Rata-Rata dan Presentase Peningkatan

\begin{tabular}{|c|c|c|c|c|c|}
\hline \multirow{3}{*}{ Area } & \multicolumn{5}{|c|}{ Flow Rate (L/menit) } \\
\hline & \multirow{2}{*}{$\begin{array}{c}14 \\
\mathrm{HV}\end{array}$} & \multicolumn{2}{|c|}{16} & \multicolumn{2}{|r|}{18} \\
\hline & & $\mathrm{HV}$ & Peningkatan & $\mathrm{HV}$ & Peningkatan \\
\hline $\mathrm{BM}$ & 141.92 & 145.40 & $2.45 \%$ & 167.13 & $17.76 \%$ \\
\hline HAZ & 150.00 & 154.07 & $2.71 \%$ & 172.16 & $14.78 \%$ \\
\hline WM & 170.39 & 189.33 & $11.12 \%$ & 205.78 & $20.77 \%$ \\
\hline
\end{tabular}

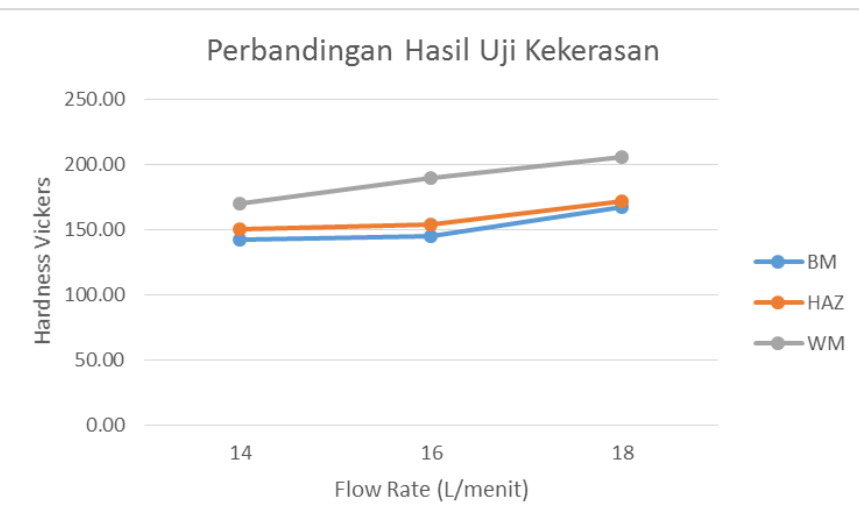

Gambar 10. Perbandingan hasil uji kekerasan.

Berdasarkan hasil uji kekerasan Vickers yang ditunjukkan pada Gambar 10, kekerasan mengalami peningkatan seiring dengan meningkatnya flow rate gas pelindung baik pada BM (Base Metal), HAZ (Heat Affected Zone), maupun WM (Weld Metal). Berdasarkan hasil uji kekerasan dapat diketahui nilai kekerasan sebagai berikut:

1. Pada daerah base metal nilai kekerasan dari $141,92 \mathrm{HV}$ pada hasil pengelasan dengan flow rate gas pelindung 14 $\mathrm{L} /$ menit. Pada hasil pengelasan dengan flow rate gas pelindung $16 \mathrm{~L} /$ menit meningkat sebanyak $2,45 \%$ menjadi $145,40 \mathrm{HV}$ dan pada hasil pengelasan dengan flow rate gas pelindung $18 \mathrm{~L} /$ menit meningkat sebanyak $17,76 \%$ menjadi $167,13 \mathrm{HV}$.

2. Pada daerah HAZ memiliki nilai kekerasan $150,00 \mathrm{HV}$ pada hasil pengelasan dengan flow rate gas pelindung 14 L/menit. Meningkat sebanyak 2,71\% menjadi 154,07 HV pada hasil pengelasan dengan flow rate gas pelindung 16 L/menit dan meningkat sebanyak $14,78 \%$ menjadi 172,16 $\mathrm{HV}$ pada hasil pengelasan dengan flow rate gas pelindung 18 L/menit.
3. Pada daerah Weld Metal memiliki nilai kekerasan 170,39 HV pada hasil pengelasan dengan flow rate gas pelindung $14 \mathrm{~L} /$ menit. Meningkat sebanyak $11,12 \%$ menjadi 205,78 HV pada hasil pengelasan dengan flow rate gas pelindung $16 \mathrm{~L} /$ menit dan meningkat sebanyak 20,77\% menjadi 205,78 HV pada hasil pengelasan dengan flow rate gas pelindung $18 \mathrm{~L} /$ menit.

Peningkatan nilai kekerasan tertinggi yaitu pada daerah weld metal karena daerah ini terjadi peleburan logam induk dengan elektroda atau filler metal dan mengalami perubahan struktur maupun sifat. Komposisi weld metal terdiri dari komponen base metal dengan tambahan dari elektroda.

\section{Analisa Hasil Uji Tarik}

Setelah dilakukan uji tarik terhadap ketiga spesimen, didapatkan data sebagai mana pada Tabel 7.

\begin{tabular}{cccccc} 
& \multicolumn{5}{c}{$\begin{array}{c}\text { Tabel.7. } \\
\text { Hasil Uji Tarik }\end{array}$} \\
\hline \hline Test & Flow & Area & Yield & Ultimate & Elongation \\
Piece & Rate & & Strength & Strength & \\
\cline { 2 - 6 } & L/menit & $\mathrm{mm}^{2}$ & Mpa & Mpa & $\%$ \\
\hline 1 & 14 & 201.10 & 415.47 & 468.40 & 22.12 \\
2 & 16 & 198.60 & 408.90 & 491.70 & 24.71 \\
3 & 18 & 202.00 & 409.70 & 470.80 & 22.86 \\
\hline \hline
\end{tabular}

Ketiga hasil pengujian tarik tersebut patah pada bagian logam induk (base metal). Dari ketiga hasil tersebut selisih nilai yield, ultimate, dan elongation tidak jauh berbeda dikarenakan patahan terjadi di daerah logam induk yang menjauhi daerah lasan.

Berdasarkan hasil pengujian tarik nilai tegangan yield, tegangan ultimate, dan elongation memenuhi rules BKI Vol. $\mathrm{V}$ Rules for Materials (Tabel.1). Dimana nilai tegangan yield minimal $235 \mathrm{~N} / \mathrm{mm}^{2}$, nilai tegangan ultimate antara $400-520 \mathrm{~N} / \mathrm{mm}^{2}$, dan nilai elongation minimal sebesar $22 \%$.

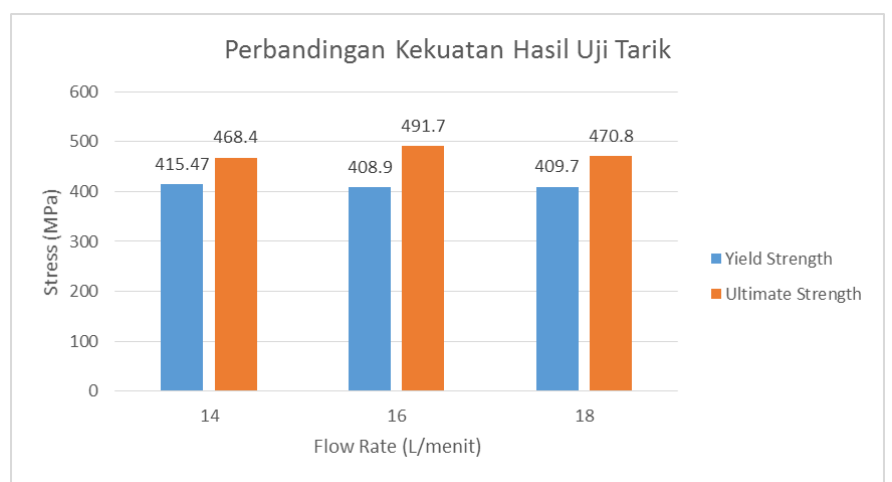

Gambar 11. Perbandingan kekuatan hasil uji Tarik.

Berdasarkan perbandingan kekuatan hasil uji Tarik (Gambar 11), hasil pengelasan dengan flow rate gas pelindung $14 \mathrm{~L} /$ menit memiliki tegangan yield tertinggi yaitu sebesar sebesar 415,47 MPa. hasil pengelasan dengan flow rate gas pelindung $16 \mathrm{~L} /$ menit memiliki tegangan yield terendah yaitu sebesar 408,90 MPa. Dan hasil pengelasan dengan flow rate gas pelindung sebesar $18 \mathrm{~L} /$ menit memiliki tegangan yield sebesar 409,70 MPa. 


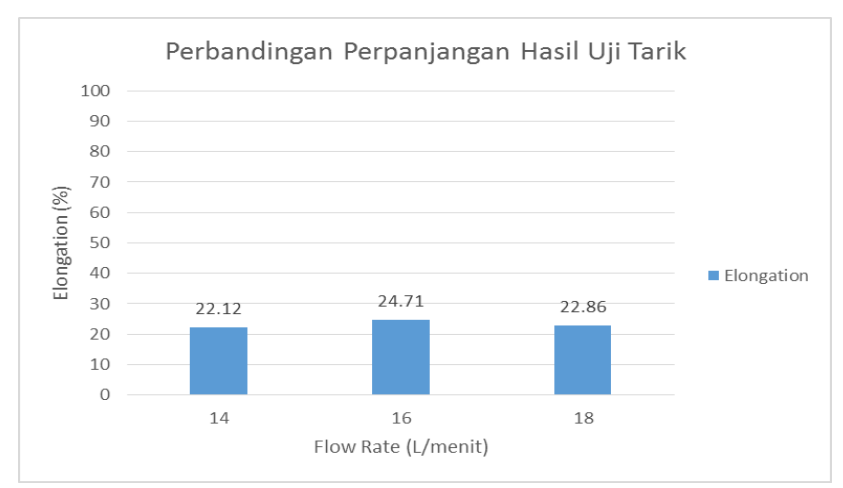

Gambar 12. Perbandingan perpanjangan hasil uji tarik.

Tegangan ultimate adalah tegangan maksimal yang dapat ditahan oleh benda uji ketika mengalami tarikan sebelum bahan uji tersebut patah. Pada hasil pengelasan dengan flow rate gas pelindung $14 \mathrm{~L} /$ menit memiliki nilai tegangan ultimate terendah yaitu sebesar 468,40 MPa. Sedangkan pada hasil pengelasan dengan flow rate gas pelindung $16 \mathrm{~L} / \mathrm{menit}$ memiliki nilai tegangan ultimate tertinggi yaitu sebesar 491,70 MPa. Dan hasil pengelasan dengan flow rate 18 L/menit memiliki nilai tegangan ultimate sebesar 470,80 MPa.

Berdasarkan perbandingan perpanjangan hasil uji Tarik (Gambar 12), hasil pengelasan dengan flow rate gas pelindung $14 \mathrm{~L} /$ menit memiliki nilai terendah yaitu sebesar $22,12 \%$. Hasil pengelasan dengan flow rate gas pelindung sebesar $16 \mathrm{~L} /$ menit memiliki nilai perpanjangan tertinggi yaitu sebesar24,71\%. Sedangkan hasil pengelasan dengan flow rate gas pelindung sebesar $18 \mathrm{~L} /$ menit memiliki nilai perpanjangan sebesar $22,86 \%$.

\section{KESIMPULAN}

Setelah dilakukan serangkaian percobaan dan analisa, didapatkan kesimpulan sebagai berikut:

1) Pengaruh variasi flow rate gas pelindung terhadap struktur mikro adalah dengan naiknya flow rate gas pelindung terlihat semakin meningkatnya jumlah struktur perlit. Hal ini disebabkan karena bertambah besarnya flow rate gas pelindung, semakin kuat tekanan hembusan gas pelindung maka semakin cepat pula laju pendinginan.

2) Pengaruh variasi flow rate gas pelindung terhadap kekerasan, semakin besar flow rate gas pelindung semakin besar pula nilai kekerasan material las. Dan kenaikan nilai kekerasan terbesar terdapat pada weld metal karena pada area tersebut terjadi peleburan logam induk dengan elektroda atau filler metal.

3) Pengaruh variasi flow rate gas pelindung terhadap kekuatan tarik adalah pada saat dilaksanakan uji tarik patahan terjadi di daerah base metal dikarenakan daerah weld metal maupun HAZ lebih keras daripada base metal. Setelah dilaksanakan uji tarik, nilai kekuatan tarik yang tidak jauh berbeda pada masing-masing tegangan yield, tegangan ultimate, maupun elongation dikarenakan mengikuti sifat dasar dan kekuatan dari dari logam induk dan tidak lebih rendah dari kekuatan tarik minimum logam induk.

\section{DAFTAR PUSTAKA}

[1] H. dan O. Wiryosumarto, Teknologi Pengelasan Logam. Jakarta: Pradnya Paramita, 2000. 